\title{
ESTUDIO SOBRE LA ACTITUD Y LAS EXPECTATIVAS DE LOS ESTU- DIANTES DEL GRADO EN TURISMO DE LA UNIVERSIDAD DE ALMERÍA
}

\author{
Rosa María Torres Crespo ${ }^{1}$
}

Universidad de Almería

\begin{abstract}
Resumen
Este trabajo de investigación tiene como fin conocer la actitud y las expectativas de los estudiantes del Grado en Turismo de la Universidad de Almería. El grado en Turismo es uno de los menos cotizados por los estudiantes en las últimas décadas, por ello es importante conocer la actitud y expectativas que presentan los estudiantes antes de comenzar el grado y tras cursar algún año de éste, qué relación existe entre estas dos variables y cuáles son los motivos por los que estos eligen entrar en el grado. Para conocer esto, se ha realizado un cuestionario que se ha pasado a los/las alumnos/as de los cuatro cursos del grado. En las siguientes páginas se muestran los resultados obtenidos, así como los análisis de frecuencias, de contingencia y la correlación de Pearson realizados. A pesar de que la mayoría de los/las alumnos/as no entran al grado por vocación, tanto las expectativas ideales como las reales de la mayoría de los estudiantes son positivas y se comprobará que existe una relación significativa entre las actitudes y las expectativas. Este TFG también presenta una parte cualitativa en la que se muestran las opiniones de los estudiantes con respecto a la carrera, las cuales son constructivas y pueden ayudar a mejorar el grado.
\end{abstract}

\section{Palabras clave:}

Turismo, Expectativas, Actitud, Universidad de Almería, Estudiantes.

\begin{abstract}
This research aims to know the attitude and expectations of the students of the Degree in Tourism at the University of Almeria. The degree in Tourism is one of the least quoted by students in recent decades, so it is important to know the attitude and expectations presented by the students before starting the degree and after completing some year of it, what relationship exists between these two variables and what are the reasons why they choose to study this degree. To know all of this, a questionnaire has been passed at the students of the four courses of degree. The results obtained and an analysis of these are shown on the following pages. Although most students do not the degree by vocation, ideal and real expectations of the students are positive and it will be verified that there is a significant relationship between attitudes and expectations. This TFG also presents a qualitative part, where we can see the opinions of students about the degree, which are constructive and can help to improve the degree in Tourism.
\end{abstract}

Key words:

Tourism, Expectations, Attitude, University of Almeria, Students

\section{Introducción}

La psicología positiva es considerada como una corriente innovadora dentro de la psicología general, surgió a finales de la década de los noventa y fue fundada por el psicólogo Martin Seligman. El principal objetivo de esta consiste en trabajar las fortalezas y virtudes humanas para conseguir el bienestar de los individuos. Son varios los psicólogos que se dedican a definir y estudiar esta corriente psicológica.

Seligman (2005) define la psicología positiva como una ciencia en la que se estudian las prácticas positivas, las auténticas características de las personas y las organizaciones que hacen fácil el desarrollo personal y que ayudan a plasmar una mejora en la calidad de vida de los individuos,

Recibido: 3 de marzo de 2020

Aceptado: 28 de abril de 2020

Correspondencia: Rosa maría Torres Crespo

Email: rosamariatc296@gmail.com mientras ayuda a reducir la psicopatología.

Ken Sheldon, Barbara Frederickson, Kevin Rathunde, Mike Csikszentmihalyi y Jon Haidt (1999) definen esta corriente como un estudio científico del funcionamiento humano óptimo.

Se han realizado numerosos estudios relacionados con la psicología positiva, como la esperanza, la felicidad, las fortalezas del carácter, los valores, las relaciones positivas, la resiliencia, etc. Dentro de esta investigación nos vamos a centrar en estudiar dos componentes de la psicología positiva, como son las expectativas y las actitudes.

La finalidad que persigue este estudio es conocer cuáles son las expectativas y las actitudes que presentan los estudiantes del grado en Turismo de la Universidad de Almería.

Actualmente, el sector turístico es uno de los sectores que más valor económico aporta a España, aunque a su vez es uno de los pocos sectores que debe poseer una titulación específica propia. Pese a que son muchos los esfuerzos que presentan las universidades para mejorar la formación de los profesionales de este sector son cada vez menos los estudiantes 
que se decantan por estudiar el Grado en Turismo en nuestro país y es que cada vez son más los artículos que hablan de la alta tasa de desempleo que existe en el sector turístico.

Los primeros estudios oficiales de Turismo datan de 1963, pero es en 1980 cuando estos estudios entran en las universidades con la introducción de los Técnicos en Empresas y Actividades Turísticas (TEAT). Empujado por un aumento de la demanda para este tipo de estudios, las universidades públicas y privadas, y escuelas de negocios ofrecen esta formación en dos niveles educativos: grado y postgrado (Rodríguez et al., 2012).

Los programas de estudio se debaten entre un marco regulatorio universitario común, determinado por la oficialidad de los programas, y la flexibilidad necesaria en el diseño curricular con el fin de facilitar la transición de la universidad a la industria (Tribe, 1997).

La formación en Turismo se presenta de forma multidisciplinar, entrelazando la formación profesional junto con las habilidades empresariales y la formación emprendedora.

Las enseñanzas de las universidades y escuelas de negocios y los programas de módulos vacaciones que desarrollan los estudiantes, hacen que la formación empresarial del sector turístico haya tenido diferentes grados de éxito en lo que respecta a contenido y enseñanza con respecto al tiempo. Si a esto le sumamos que son escasas las investigaciones que se han observado sobre la relación entre la actitud y las expectativas de los estudiantes hacia el grado en turismo, nos lleva a pensar que es necesario investigar cuáles son las opiniones de los estudiantes en relación con el grado, antes y después de cursarlo y qué actitud muestran hacia éste.

En la psicología positiva influye mucho la actitud de las personas, ya que es necesario que las personas tengan una actitud positiva hacia otras personas, objetos, situaciones, etc.

Las actitudes son evaluaciones globales que se hacen las personas entre sí o a otras ideas o cosas, a éstas se les denomina, "objetos de actitud" (Morales, 2007). De una forma más exacta, las actitudes tienden a ser la manera positiva o negativa con las que las personas juzgan cualquier aspecto de la realidad (Eagly y Chaiken, 1998).

La actitud está compuesta por tres componentes, que debemos evaluar para obtener la información necesaria sobre los estudiantes del grado en turismo.

Un componente cognitivo, el cual se define como la capacidad que tienen las personas de tratar la información que reciben a través de los sentidos para convertirla posteriormente en conocimiento (Morales, 2007). De aquí derivan los pensamientos, que son aquellas acciones que fabrica la mente sobre una situación, persona o cosa. Gracias a este factor, se podrán estudiar los pensamientos de los estudiantes con respecto al grado.

Un componente afectivo, que se trata del conjunto de emociones y sentimientos que se tienen sobre algo o alguien, éstos son estados mentales totalmente subjetivos, cada individuo experimenta las emociones y sentimientos de una forma particular y concreta, y esta puede deberse al aprendizaje o experiencias que haya tenido previamente. (Morales, 2007). Gracias a este factor observaremos cuáles son los sentimientos que los estudiantes presentan hacia el grado.

Y, por último, un componente comportamental. El comportamiento es la manera en la que los seres vivos muestran sus intenciones de conducta, se trata de la forma en la que éstos reaccionan ante los estímulos. El comportamiento está formado por una serie de elementos, como son la cultura, las creencias o las normas (Morales, 2007). Este factor nos permitirá estudiar cuál es la conducta que mantienen los estudiantes hacia el grado en Turismo.

La actitud que el estudiante presenta hacia sus estudios está directamente relacionada con las expectativas que éste tiene sobre el grado que cursa.
En el proceso de la creación de las expectativas, intervienen diversas variables que hacen que para cada persona y situación existan expectativas diferentes. La palabra expectativa viene del latín "exspectatum", que quiere decir esperanza de realizar o conseguir algo. Se conoce como expectativa a una creencia de lo que ocurrirá en el futuro, la cual puede ser realista o no (Cosacov, 2007) y la imágen anticipada de lo que ocurrirá en un futuro (Merhi, 2011).

Las expectativas son el resultado de la interacción de la persona con la situación en la que se encuentra. En el concepto universitario, estas implican la decisión de qué titulación escoger, y qué percepción se tiene de los años de universidad. La capacidad que muestra el estudiante para crear sus propias anticipaciones futuras hace que éste cree expectativas, y éstas se precisen usando el sistema de formación (el grado de servicio y fiabilidad esperada, las preferencias, intereses, etc.), llegando a ser las expectativas que presentará el estudiante cuando mantenga relación con los servicios universitarios (Alonso, 1999).

Debemos tener en cuenta que las expectativas son el resultado causado por la percepción subjetiva del ambiente, por lo que al ser algo muy diferente en cada persona, es muy difícil que todos los estudiantes tengan la misma percepción del grado, y no todos esperen lo mismo de éste. Lo que sí es seguro que todos los estudiantes esperan antes de entrar a cualquier grado universitario, es que esta etapa sea aquella que les conduzca hacia el futuro deseado.

Hace algunas décadas, los estudiantes decidían estudiar un grado pensando en que, éste sería aquello en lo que se dedicarían en el futuro. Solían interesarse en los contenidos y asignaturas que se impartían dentro del grado para así poder estar más preparados. Tras terminar los estudios superiores, lo que se debía hacer era incorporarse al mundo laboral, ya que el modelo que había que seguir era cursar una carrera universitaria, tener preparación y encontrar un trabajo relacionado con esta formación. No obstante, esto ya no es así, ya que se ha podido ver como el mercado laboral no ha sido capaz de dar respuesta al gran número de graduados universitarios de los últimos tiempos. (Álvarez, González y López, 2009)

La creciente demanda turística en España hace necesaria la existencia de un personal que esté altamente cualificado y sea competente en el puesto que desempeñe. Si se visiona de una manera estratégica, es importante que el estudiante transite por la carrera sobre la base de sus expectativas profesionales-laborales.

Por todo esto, los estudiantes que ingresan a la universidad podrían tener diferentes expectativas en referencia al tipo de educación y el futuro laboral que les espera. La actitud y las expectativas que tenga un estudiante hacia su grado es muy importante, ya que una actitud positiva hará que este tenga un desempeño más favorable y producirá altas expectativas con respecto a su futuro laboral.

\section{Objetivos}

\section{Objetivo general}

-Investigar la relación que existe entre la actitud y las expectativas de los estudiantes con respecto al Grado en Turismo en la Universidad de Almería.

\section{Objetivos específicos}

-Conocer cuáles son los componentes de la actitud (factor cognitivo, factor comportamental y factor afectivo) que más valoran los estudiantes en el Grado en Turismo de la Universidad de Almería.

-Estudiar cuáles son las expectativas de los estudiantes del grado en Turismo de la Universidad de Almería.

-Investigar si existe relación entre los factores actitudinales (cognitivo, 
comportamental y afectivo) y las expectativas de los estudiantes con respecto al Grado en Turismo en la Universidad de Almería.

\section{Método}

\section{Muestra}

Se ha llevado a cabo un estudio descriptivo transversal, con un tipo de muestreo no probabilístico de carácter consecutivo, ya que este se define como similar al muestreo por conveniencia, excepto que intenta incluir a todos los sujetos accesibles como parte de la muestra (Walpole \& Myers, 1996). La muestra seleccionada para esta investigación es un total de 105 alumnos/as del Grado en Turismo de la Universidad de Almería, pertenecientes a los cuatro años del grado.

Del total de alumnos/as que han respondido la encuesta, el $76 \%$ de estos, es decir 80 de ellos, pertenecen al sexo femenino mientras que el $24 \%$, es decir 25 , son de sexo masculino.

De los 105 alumnos/as encuestados, el $88 \%$ de ellos tienen una edad comprendida entre los 18 y 25 años, el $10 \%$ tiene entre 25 y 35 años y únicamente el $2 \%$ de los encuestados, tienen una edad superior a 35 años.

Por último, de los cuatro cursos del grado en Turismo de la Universidad de Almería, los/las alumnos/as que más han respondido al cuestionario son los de $4^{\circ}(34 \%)$, seguidos de los/las alumnos/as de $3^{\circ}$ y $1^{\circ}$ ( $26 \%$ y $25 \%$, respectivamente). De los que menos respuesta se ha obtenido es de los/las alumnos/as de $2^{\circ}$, de los cuales, únicamente ha respondido al cuestionario un $15 \%$.

En síntesis, de los 105 alumnos/as encuestados, la gran mayoría son de sexo femenino, sus edades están comprendidas entre 18 y 25 años y pertenecen al $4^{\circ}$ curso del grado, es decir, están a pocos meses de acabar éste.

\section{Instrumento}

Para obtener toda la información necesaria para la investigación de este TFG, he confeccionado un cuestionario "ad-hoc", debido a la carencia de una muestra prediseñada que incluyera las variables estudiadas. Este presenta una escala de alternativa múltiple.

El cuestionario consta de 19 preguntas de las cuales 16 de éstas son de carácter cuantitativo y 3 de carácter cualitativo, las 3 primeras preguntas son sociodemográficas, en ellas se cuestiona sobre el sexo, la edad y el curso de los estudiantes, tras éstas se presentan las 16 preguntas restantes, de las cuales la primera pregunta, informa del motivo por el que los estudiantes se han decantado por estudiar el Grado en Turismo, tres preguntas relacionadas con la variable "expectativas", las cuales informan de las expectativas de los estudiantes antes y después de cursar algún año del grado, seis preguntas referentes a la actitud de los estudiantes, las cuales se dividen en dos referentes al factor cognitivo, dos referentes al factor comportamental y dos referentes al factor afectivo. Las preguntas restantes son cuestiones abiertas, de carácter cualitativo e informan de la opinión de los estudiantes con respecto al grado y oportunidades de empleo futuro, de si se arrepienten de haberlo elegido, de si modificarían algo del grado y en caso positivo el qué, de si consideran que la Universidad de Almería tiene mejor nivel académico que las universidades donde han realizado la Erasmus, en caso de que hayan realizado esta y de si consideran que el grado está realmente valorado por la sociedad.

Únicamente se presentarán análisis de consistencia de aquellas variables que permiten la realización de este análisis.

En lo que respecta a la variable expectativas, ejemplos de las preguntas diseñadas son: “¿Cómo eran sus expectativas antes de comenzar el grado?”, “¿Cómo son sus expectativas tras cursar algún año del grado o finalizarlo? o "¿Considera que se han cumplido sus expectativas tras cursar algún año del grado?”. El grado de consistencia, medido mediante el coeficiente Alfa de Cronbach, que reflejan los datos referentes a la variable expectativas, es de 0.50, valor aceptable según Nunnally (1967).

Por otra parte, con respecto a la variable actitud, estos son algunos ejemplos de las preguntas diseñadas para cada factor:

Factor cognitivo: “¿Cuál era su pensamiento antes de comenzar el grado?”, "Una vez cursado algún año del grado, ¿Sigue manteniendo el mismo pensamiento?".

Factor comportamental: "Cuál era su comportamiento antes de comenzar el grado?”, “Ha cambiado su comportamiento tras cursar algún año del grado?".

Factor afectivo: “¿Tenía algún sentimiento hacia el grado antes de comenzarlo?”, “¿Ha cambiado ese sentimiento tras cursar algún año?”

Para finalizar, el grado de consistencia de los datos referentes a la variable actitud, medido también mediante el coeficiente Alfa de Cronbach, es de 0.50 , valor aceptable según Nunnally (1967).

\section{Procedimiento y Análisis}

El cuestionario, ha sido realizado mediante Google Formularios y el canal utilizado para recoger la muestra ha sido internet. La encuesta se ha pasado a los/las alumnos/as de manera online a través de correo electrónico y apps de mensajerías, durante un tiempo limitado de 15 días, desde el 11 de marzo de hasta el 26 de marzo de 2018.

Una vez obtenidos los datos, se pasó a la medición de éstos, mediante el uso del programa IBM SPSS Statistics en su versión 25. Con este programa se realizaron análisis estadísticos descriptivos, tablas de frecuencias y porcentajes, tablas de contingencia y análisis de correlación de Pearson.

\section{Resultados}

A continuación, a lo largo de las siguientes páginas, encontraremos varias tablas y gráficos que explican un análisis detallado de las respuestas al cuestionario que se le hizo llegar a los estudiantes de turismo de la Universidad de Almería.

Este apartado consta de dos bloques, un bloque I en el que se presentarán aquellos resultados de carácter cuantitativo y un bloque II en el que se presentarán aquellos resultados de carácter cualitativo.

Dentro del bloque I, encontraremos aquellos resultados pertenecientes a las preguntas en la que se cuestiona el motivo por el cual los estudiantes de turismo decidieron comenzar el grado, las expectativas ideales y reales de los estudiantes, el pensamiento, el sentimiento y el comportamiento de éstos antes y después de comenzar el grado, las expectativas de los estudiantes en función del curso en que se encuentran, la relación entre las expectativas y la actitud de los estudiantes, si éstos han realizado una beca Erasmus dentro del grado y si es así, que universidad consideran que tiene un mayor nivel académico y, por último, se les cuestiona a los/las alumnos/as si consideran que el grado en turismo tiene salidas laborales. Dentro de este bloque, podemos encontrar, un análisis descriptivo de frecuencias, un análisis de contingencia y un análisis de correlación de Pearson.

En lo que respecta al bloque II, dentro de éste encontraremos aquellas opiniones que los estudiantes del grado mantienen sobre éste y que nos resultan de interés para la realización de las conclusiones de esta investigación. Las preguntas que encontramos dentro de éste son: si se sienten arrepentidos de elegir este grado y el por qué, si modificarían algo del grado y en caso positivo el por qué y si consideran que el grado en Turismo está realmente valorado por la sociedad. 


\section{Bloque 1. Resultados cuantitativos}

\section{Análisis de Frecuencias}

La primera pregunta que se le hizo a los/las alumnos/as fue de carácter introductorio, con ésta se pretendía averiguar el porqué de la elección por parte de los/las alumnos/as del grado en turismo como carrera universitaria. Esta pregunta está compuesta por varias respuestas, las cuales son de carácter múltiple, por lo que los/las alumnos/as, podían elegir más de una respuesta alternativa.

Como podemos observar en el Gráfico 1, son varios los motivos por los que los/las alumnos/as eligieron estudiar el grado en Turismo en la UAL.

De 105 alumnos/as que respondieron la encuesta, únicamente el 12\% de ellos eligieron estudiar turismo por vocación. El 26\% de los/las alumnos/as, marcaron que uno de los motivos era aprender idiomas dentro del grado, el $21 \%$ de éstos eligieron el grado esperanzados en la oportunidad laboral futura, el $28 \%$ de los/las alumnos/as coinciden en la atracción por trabajar en agencias de viajes, hoteles, oficinas de turismo, etc. El $2 \%$ de los/las alumnos/as, entraron al grado por imposición de familiares y el $9 \%$ lo hicieron por no poder entrar en su primera opción. Por último, el $2 \%$ de los/las alumnos/as, eligieron poner otro motivo ellos mismos, y argumentan que entraron al grado por casualidad, por estudiar algo, por las salidas académicas del grado y porque es un grado que estudia muchas ramas.

Gráfico 1

Motivos que llevan al estudiante a elegir el Grado en Turismo

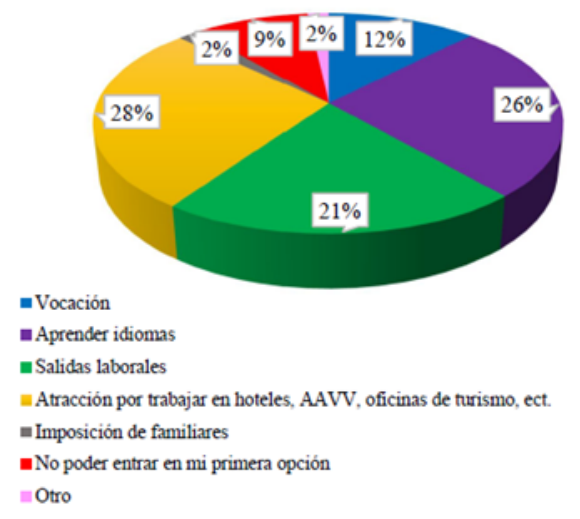

En síntesis, la mayoría de los/las alumnos/as coinciden en que no eligieron estudiar el grado en Turismo por vocación, sino porque se sentían atraídos por trabajar en hoteles, agencias de viajes, oficinas de turismo, etc., por aprender idiomas, o por las salidas laborales de este grado.

A continuación, pasamos a analizar los resultados referentes a la variable expectativas. Se plantean tres preguntas correspondientes a esta variable, mediante las cuales se pretende averiguar las expectativas reales e ideales que tienen los estudiantes con respecto al grado.

La primera pregunta sobre esta variable que se le hizo a los/las alumnos/as fue la siguiente:

Pregunta 1 ¿Cómo eran sus expectativas antes de comenzar el grado?

Como podemos observar en la Tabla 1, el 70\% de los estudiantes comenzaron el grado con un alto porcentaje de expectativas positivas. El 27\% de éstos, dijeron que no tenían expectativas con respecto al grado $\mathrm{y}$, por último, únicamente el $3 \%$ de los estudiantes entraban al grado con unas expectativas negativas hacia éste.
Tabla 1

Expectativas ideales

\begin{tabular}{lccc}
\hline Categoría & $\begin{array}{c}\text { Frecuen- } \\
\text { cia }\end{array}$ & $\begin{array}{c}\text { Porcenta- } \\
\text { je }\end{array}$ & $\begin{array}{c}\text { Porcentaje } \\
\text { válido }\end{array}$ \\
\hline $\begin{array}{c}\text { Tenía expectativas positi- } \\
\text { vas }\end{array}$ & 73 & 70 & 7 \\
$\begin{array}{l}\text { Tenía expectativas negati- } \\
\text { vas }\end{array}$ & 3 & 3 & 3 \\
No tenía expectativas & 29 & 27 & 27 \\
$\quad$ Total & 105 & 100.0 & 100.0 \\
\hline
\end{tabular}

Posteriormente se les preguntó a los estudiantes si se habían cumplido esas expectativas.

Pregunta 2. Una vez cursado algún año del grado, ¿Considera que se han cumplido sus expectativas?

Como podemos observar en la Tabla 2, aunque por poca diferencia, la mayoría de los estudiantes, el 51\%, consideran que no se han cumplido sus expectativas, mientras que el 49\% considera que éstas, sí se han cumplido.

Tabla 2

Expectativas reales

\begin{tabular}{|c|c|c|c|}
\hline Categoría & Frecuencia & Porcentaje & $\begin{array}{c}\text { Porcentaje } \\
\text { válido }\end{array}$ \\
\hline $\mathrm{Si}$ & 51 & 49 & 49 \\
\hline No & 54 & 51 & 51 \\
\hline Total & 105 & 100.0 & 100.0 \\
\hline
\end{tabular}

La última pregunta sobre expectativas que se hizo a los estudiantes es la que se presenta en el Gráfico 2, éste nos muestra que la mayoría de los estudiantes (52\%) al acabar algún año del grado, tienen expectativas positivas hacia éste.

El 23\% de los estudiantes tienen expectativas negativas hacia el grado, mientras que el $15 \%$, mantienen las mismas expectativas con las que entraron y el $10 \%$ de los estudiantes muestran que no tienen ninguna expectativa hacia el grado.

Pregunta 3: ¿Cuáles son sus expectativas tras cursar algún año del grado?

Gráfico 2

Expectativas de los estudiantes tras cursar algún año del grado

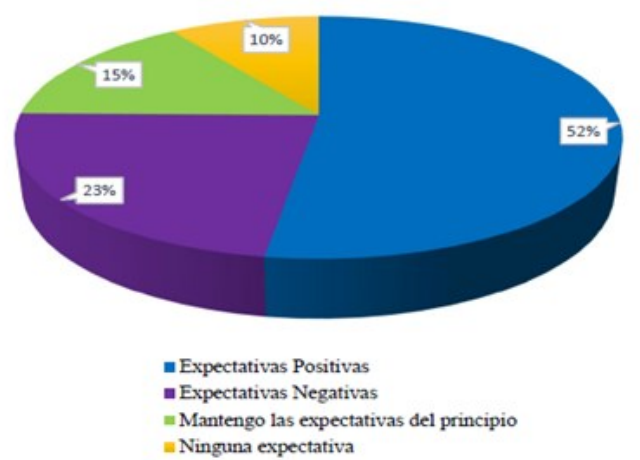


Para terminar con las expectativas tras cursar algún año del grado, se ha desarrollado un análisis personalizado, para averiguar qué expectativas presentan los estudiantes en función del curso en que se encuentran, y estos son los resultados:

Como podemos observar en la Tabla 4, los/las alumnos/as de primer curso son los que más consideran que se han cumplido sus expectativas, ya que el $17 \%$ de los/las alumnos/as dicen que, sí se han cumplido, frente al $8 \%$ de los/las alumnos/as que consideran que no se han cumplido sus expectativas. Con respecto a los/las alumnos/as de segundo curso, vemos que esto ha cambiado y el 7\% considera que sí se han cumplido sus expectativas, frente al $9 \%$ que no creen que estas se hayan cumplido. De los/las alumnos/as de tercer curso, el 14\% de ellos, consideran que, sí se han cumplido sus expectativas, frente al $11 \%$ que no creen que esto haya sido así. Por último, vemos que, de los/las alumnos/as de cuarto curso, la gran mayoría, el $24 \%$ considera que no se han cumplido sus expectativas, frente al $10 \%$ que consideran que esto sí ha sido así.

Tabla 4

Expectativas reales con respecto al curso

\begin{tabular}{|c|c|c|c|c|c|}
\hline & & \multicolumn{4}{|c|}{ Curso } \\
\hline & & $1^{\circ}$ & $2^{\circ}$ & $3^{\circ}$ & $4^{\circ}$ \\
\hline Una vez & & $\begin{array}{c}\text { Recuento } \\
(\%)\end{array}$ & $\begin{array}{l}\text { Recuento } \\
(\%)\end{array}$ & $\begin{array}{c}\text { Recuento } \\
(\%)\end{array}$ & $\begin{array}{l}\text { Recuento } \\
(\%)\end{array}$ \\
\hline $\begin{array}{l}\text { algún año } \\
\text { del grado, } \\
\text { Considera }\end{array}$ & $\begin{array}{l}\mathrm{S} \\
\mathrm{i}\end{array}$ & $18(17)$ & 7 (7) & $15(14)$ & $11(10)$ \\
\hline $\begin{array}{l}\text { que se han } \\
\text { cumplido } \\
\text { sus expecta- }\end{array}$ & $\begin{array}{l}\mathrm{N} \\
\mathrm{o}\end{array}$ & $8(8)$ & $9(9)$ & $12(11)$ & $25(24)$ \\
\hline
\end{tabular}

Como una síntesis general, se puede ver que, los/las alumnos/as empezaron el grado con altas expectativas positivas y a medida que han ido cursando años, las expectativas han bajado, pero aun así siguen siendo mayor las expectativas positivas que las negativas.

En lo que respecta a la variable actitud, las preguntas están divididas en tres bloques (Factor cognitivo, Factor comportamental y Factor afectivo) y cada uno de ellos está compuesto por dos preguntas.

En este apartado vamos a encontrar dos cuestiones, la primera referente a un pensamiento previo sobre el grado y la segunda referente a un pensamiento posterior a algún año del grado.

En primer lugar, con respecto al factor cognitivo, la primera pregunta que se le formuló a los estudiantes fue la siguiente: ¿Cuál era su pensamiento antes de comenzar el grado? Para ésta, los estudiantes tenían una serie de respuestas múltiples que podían seleccionar.

Como se puede observar en el Gráfico 3, de todas las respuestas que se les propusieron a los/las alumnos/as, son aprender diferentes idiomas $(27 \%)$ y aprender sobre el sector turístico (23\%), lo que más pensado tenían hacer los/las alumnos/as, seguidos de estudiar asignaturas interesantes $(18 \%)$, hacer excursiones y viajes $(16 \%)$ y conocer gente $(15 \%)$, únicamente el $1 \%$ de los/las alumnos/as, tenían pensado hacer otras cosas, estos dijeron que pensaban aprender diferentes culturas y aprender historia artística y cultural.

Posteriormente se les preguntó a los estudiantes, si seguían manteniendo ese pensamiento tras cursar algún año del grado.
Gráfico 3

Pensamiento de los estudiantes antes de comenzar el grado

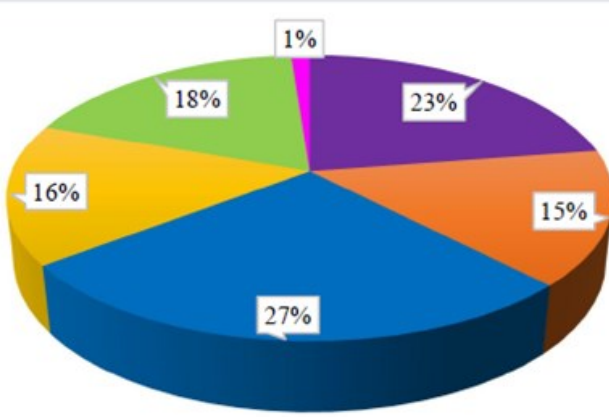

a Aprender sobre el sector turistico $\approx$ Conocer gente

- Aprender diferentes idiomas $\quad$ Hacer excursiones $\mathrm{y}$ viajes

$m$ Estudiar asignaturas interesantes $=$ Otros

Como podemos observar en la Tabla 5 , el $56 \%$ de los estudiantes considera que su pensamiento ha cambiado, mientras que el $44 \%$ mantiene el mismo pensamiento que al comenzar el grado.

Tabla 5

Pensamiento posterior a algún año del grado

\begin{tabular}{lccc}
\hline \multicolumn{1}{c}{ Categoría } & Frecuencia & Porcentaje & $\begin{array}{c}\text { Porcenta- } \\
\text { je }\end{array}$ \\
\hline Mantengo el mismo pensamiento & 46 & 44 & 44 \\
Mi pensamiento ha cambiado & 59 & 56 & 56 \\
Total & 105 & 100.0 & 100.0 \\
\hline
\end{tabular}

En lo referente al segundo factor, el factor comportamental, igual que en el factor cognitivo, se les plantearon dos cuestiones a los estudiantes en las que se pretendía averiguar el comportamiento previo y posterior de los estudiantes sobre el grado. La primera pregunta que se le formuló a los/las alumnos/as era sobre el comportamiento que estos tenían antes de comenzar el grado, el cuestionario daba tres alternativas de respuesta, y los/las alumnos/as debían elegir una de ellas.

Como podemos observar en la Tabla 6, la mayoría de los encuestados (casi $45 \%$ ) se enfrentaba al grado con curiosidad y sin miedo al fracaso. Por otro lado, el 36\% de los encuestados, tenían un comportamiento menos positivo, pues se presentaban con miedo a no superar las asignaturas. El porcentaje restante (19\%), tenían un comportamiento indiferente hacia éste.

Tabla 6

Comportamiento previo al grado

$\begin{array}{llll}\text { Categoría } & \text { N } & \% & \% \text { válido }\end{array}$

Me enfrentaba al grado con

curiosidad y sin miedo al fracaso

$47 \quad 45$

Me enfrentaba al grado con miedo a no superar las asignaturas

Mi comportamiento era indiferente

Total

20

$105 \quad 100$

100 
Posteriormente, igual que para el factor anterior, se les preguntó a los estudiantes si mantenían ese comportamiento o había cambiado.

En la Tabla 7, podemos observar que al igual que el pensamiento, el comportamiento de la mayoría de los/las alumnos/as (56\%), ha cambiado, mientras que el $44 \%$ de los encuestados, mantienen el mismo comportamiento de cuando empezó

Por último, en lo que respecta al factor afectivo, al igual que el resto de los factores, en este se presentan dos cuestiones, una correspondiente al sentimiento previo de los/las alumnos/as hacia el grado y otra referente al sentimiento de los/las alumnos/as, tras cursar algún año del grado. La primera pregunta que se formuló a los/las alumnos/as era sobre el sentimiento que tenían éstos hacia el grado antes de comenzarlo, y al igual que en el factor cognitivo, se les ofreció una serie de respuestas múltiples, en las que podían elegir más de una alternativa de respuesta.

Como se puede observar en el Gráfico 4, el 39\% de los/las alumnos/as, se sentía atraído hacia el grado, el 31\% dijo que se sentía atraído por la universidad de Almería, y el 30\% restante no manifestaba ningún sentimiento hacia el grado.

Tabla 7

Comportamiento posterior a algún año del grado

\begin{tabular}{cccc}
\hline Categoría & $\mathbf{N}$ & \% & \% válido \\
\hline $\begin{array}{c}\text { Mantengo el mismo } \\
\text { comportamiento }\end{array}$ & 46 & 44 & 44 \\
$\begin{array}{c}\text { Mi comportamiento ha } \\
\text { cambiado }\end{array}$ & 59 & 56 & 56 \\
Total & 105 & 100 & 100 \\
\hline
\end{tabular}

Gráfico 4

Sentimiento previo de los estudiantes hacia el grado

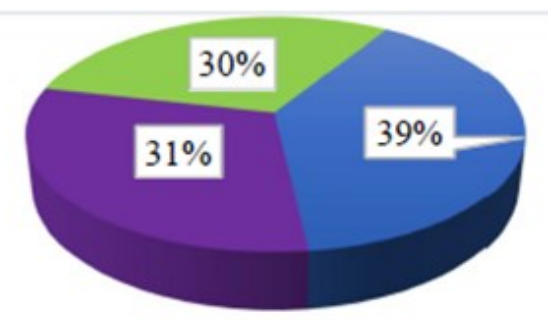

\section{$\square$ Me sentia atraido hacia el grado \\ - Me sentia atraido hacia la universidad \\ = No tenia ningún sentimiento hacia el grado}

Al igual que en los otros dos factores, se les preguntó a los encuestados si tras cursar algún año del grado, habían cambiado sus sentimientos De nuevo, podemos observar en la Tabla 8 , que el sentimiento de la mayoría de los/las alumnos/as (54\%) ha cambiado, mientras que el $46 \%$, continúa con el mismo sentimiento.
Tabla 8

Sentimiento tras cursar algún año del grado

\begin{tabular}{cccc}
\hline Categoría & N & \% & \% válido \\
\hline $\begin{array}{c}\text { Mantengo el mis- } \\
\text { mo sentimiento }\end{array}$ & 48 & 46 & 46 \\
Mi sentimiento ha cambiado & 57 & 54 & 54 \\
Total & 105 & 100 & 100 \\
\hline
\end{tabular}

En síntesis, como hemos podido observar en las Tablas 5, 7 y 8, a medida que los/las alumnos/as han cursado algún año del grado, su pensamiento, su comportamiento y su afecto con respecto al grado ha ido cambiando.

Para seguir con el análisis de resultados, la siguiente pregunta que se le hizo a los estudiantes, fue si habían realizado alguna beca Erasmus. Como podemos observar en la Tabla 9, 15 estudiantes (14\% de los encuestados) afirman haber realizado una beca erasmus, mientras que 90 de ellos (el 86\%) no han realizado esta beca.

Tabla 9

Alumnos/as con beca Erasmus

\begin{tabular}{cccc}
\hline Categoría & Frecuencia & Porcentaje & $\begin{array}{c}\text { Porcentaje } \\
\text { válido }\end{array}$ \\
\hline $\mathrm{Si}$ & 15 & 14 & 14 \\
$\mathrm{No}$ & 90 & 86 & 86 \\
Total & 105 & 100 & 100 \\
\hline
\end{tabular}

La siguiente pregunta que se le realizó a los estudiantes (en este caso, a los que respondieron positivamente a la pregunta anterior) fue si consideraban que había diferencia de nivel académico entre la universidad donde han cursado la beca Erasmus y la UAL.

La Tabla 10 nos indica que de los 15 encuestados, que en el caso anterior afirmaron realizar la beca ERASMUS, el 9\% de ellos, considera que el nivel académico es mayor en su universidad de Erasmus mientras que el $3 \%$ considera que el nivel académico es mayor en la UAL. Únicamente el 2\% de los encuestados, afirma que el nivel académico es igual en ambas universidades.

Tabla 10 .

Nivel académico de las universidades

\begin{tabular}{cccc}
\hline Categoría & Frecuencia & Porcentaje & $\begin{array}{c}\text { Porcentaje } \\
\text { válido }\end{array}$ \\
\hline $\begin{array}{c}\text { Sí, el nivel académico es } \\
\text { mayor en mi universidad de } \\
\text { Erasmus }\end{array}$ & 10 & 9 & 62 \\
$\begin{array}{c}\text { Sí, el nivel académico es } \\
\text { mayor en mi universidad } \\
\text { actual }\end{array}$ & 3 & 3 & 20 \\
$\begin{array}{c}\text { No, el nivel académico es el } \\
\text { mismo }\end{array}$ & 2 & 2 & 18 \\
Total & 15 & 14 & 100 \\
Perdidos & & 86 & \\
Sistema & 90 & 100 & \\
\hline Total & 105 & & \\
\hline
\end{tabular}


Posteriormente, la pregunta que se le formuló a los estudiantes fue si consideraban que al acabar el grado les iba a ser difícil conseguir trabajo.

Como podemos observar en la Tabla 11, el 77\% de los/las alumnos/as coinciden en que, tras realizar el grado en Turismo, es difícil encontrar trabajo, mientras que el $23 \%$ restante, considera que Turismo, es un grado que tiene muchas salidas laborales.

Tabla 11

Dificultad para encontrar trabajo

\begin{tabular}{cccc}
\hline Categoría & Frecuencia & Porcentaje & $\begin{array}{c}\text { Porcentaje } \\
\text { válido }\end{array}$ \\
\hline $\begin{array}{c}\text { Si, es difícil } \\
\text { encontrar trabajo } \\
\text { tras realizar la } \\
\text { carrera }\end{array}$ & 81 & 77 & 77 \\
$\begin{array}{c}\text { No, Turismo es } \\
\text { un grado con } \\
\text { muchas salidas }\end{array}$ & 24 & 23 & 23 \\
$\quad$ Total & 105 & 100 & \\
\hline
\end{tabular}

Análisis de Contingencia

A continuación, se presenta un análisis de contingencia para comprobar la relación que existe entre las expectativas reales de los estudiantes y cada uno de los componentes de la variable actitud. Para ello se presentan varios gráficos.

Cómo se puede observar en el gráfico 5, de aquellos/as alumnos/as que mantienen su pensamiento con respecto al grado, el $24 \%$ presentan expectativas positivas, el $10 \%$ de estos mantienen las expectativas del principio, mientras que un $6 \%$ presentan expectativas negativas y el $3 \%$ restante no presenta ninguna expectativa.

Con respecto a aquellos de los cuales ha cambiado su pensamiento, con respecto al grado, vemos que el $29 \%$ tienen expectativas positivas, el $16 \%$ expectativas negativas, sólo el 5\% mantienen las expectativas del inicio del grado y el $7 \%$ no presentan expectativas.

Gráfico 5

Relación entre factor cognitivo y las expectativas reales de los estudiantes

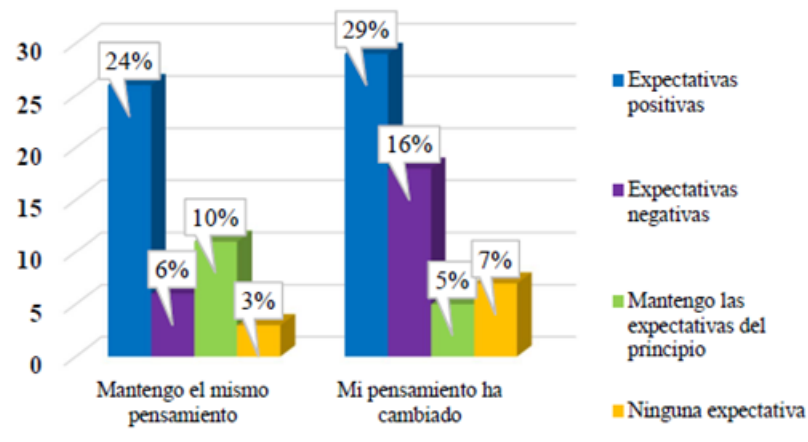

Como se puede observar en el gráfico 6 , de aquellos/as alumnos/as que mantienen su sentimiento con respecto al grado, el $29 \%$ presentan expectativas positivas, el $13 \%$ de estos mantienen las expectativas del principio, mientras que un $3 \%$ presentan expectativas negativas y el otro $3 \%$ no presenta ninguna expectativa.

Con respecto a aquellos de los cuales ha cambiado su sentimiento, con respecto al grado, vemos que el $23 \%$ tienen expectativas positivas, el $19 \%$ expectativas negativas, sólo el $4 \%$ mantienen las expectativas del inicio del grado y el $6 \%$ no presentan expectativas.

\section{Gráfico 6}

Relación entre el factor afectivo y las expectativas reales de los estudiantes

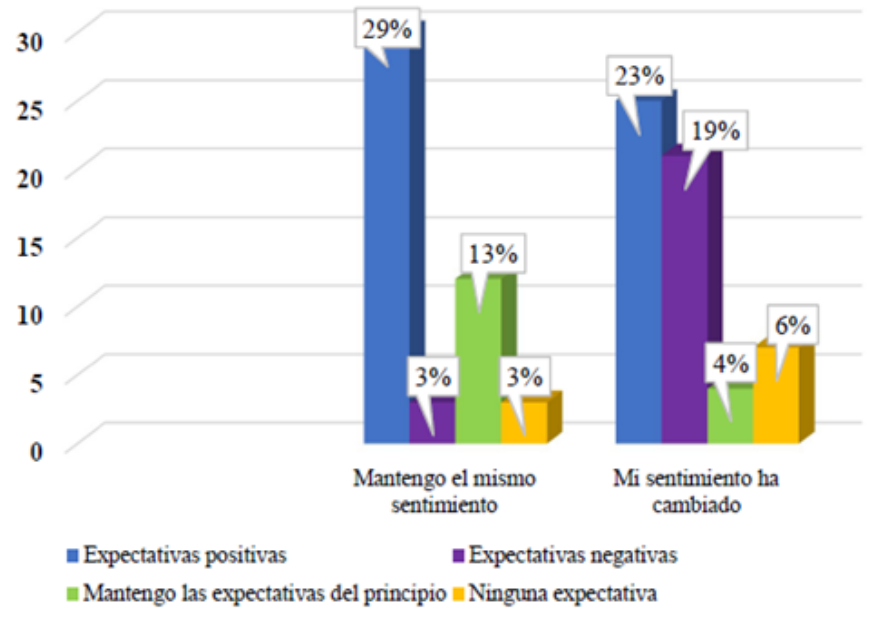

En lo que respecta al gráfico 7, se puede observar que, de aquellos/as alumnos/as que mantienen su comportamiento con respecto al grado, el $26 \%$ presentan expectativas positivas, el $12 \%$ de estos mantienen las expectativas del principio, mientras que un $3 \%$ presentan expectativas negativas y el otro $3 \%$ no presenta ninguna expectativa.

Con respecto a aquellos de los cuales ha cambiado su comportamiento, con respecto al grado, vemos que el $28 \%$ tienen expectativas positivas, el $19 \%$ expectativas negativas, sólo el 3\% mantienen las expectativas del inicio del grado y el $6 \%$ no presentan expectativas.

Gráfico 7

Relación entre el factor comportamental y las expectativas reales de los estudiantes

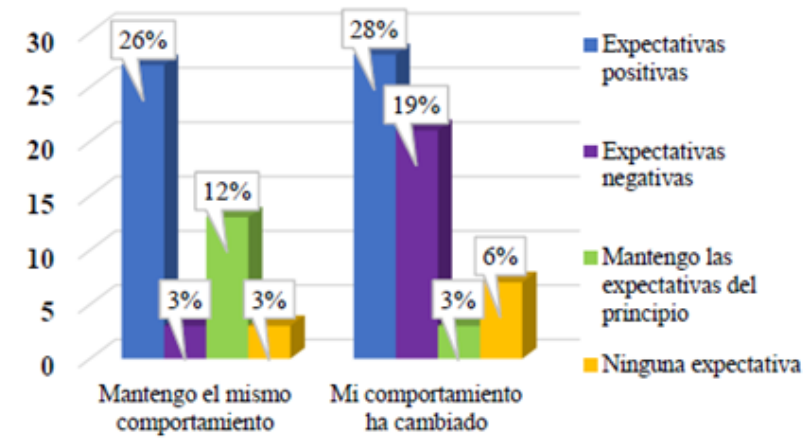

En síntesis, cómo hemos podido comprobar en las distintas tablas de contingencia, tanto los/las alumnos/as que mantienen su pensamiento, comportamiento y sentimiento de antes de comenzar el grado, como aquellos/as que han cambiado éstos, mantienen en su mayoría expectativas positivas.

\section{Análisis de Correlación}

A continuación, para conocer si existe relación entre la variable expectativa y la variable actitud, se ha llevado a cabo un análisis de correlación de Pearson, en el que se comprueba, por una parte, la relación de los componentes de la variable actitud con las expectativas de los estudiantes antes de 
comenzar el grado (ver Tabla 12) y, por otra parte, la relación de estos con las expectativas de los estudiantes tras cursar algún año del grado (ver Tabla 13).

En la Tabla 12, podemos observar que no existe ninguna relación entre las expectativas ideales de los estudiantes y los componentes cognitivo, afectivo y comportamental de la actitud. No obstante, sí existe relación intraescalar entre los distintos componentes:

Existe una relación estadísticamente significativa en el par factor cognitivo vs factor afectivo. $(\mathrm{r}=.654$, significación de 0,001$)$.

Existe una relación estadísticamente significativa en el par factor afectivo vs factor comportamental. $(\mathrm{r}=.654$, significación de 0,001$)$.

Existe una relación estadísticamente significativa en el par factor cognitivo vs factor comportamental. $(\mathrm{r}=.497$, significación de 0,001$)$.

Tabla 12

Relación de los componentes de la variable actitud con las expectativas ideales

$\begin{array}{lll}\text { Una vez que ha } & & \\ \text { cursado algin año } & \text { ¿Ha cambiado su } & \text { ¿Ha cambiado su } \\ \text { del grado, ¿Sigue } & \text { ¿Hentimiento por el } & \text { comportamiento tras } \\ \text { manteniendo el } & \text { grado tras cursar } & \text { cursar algún año del } \\ \text { mismo pensamiento } & \begin{array}{l}\text { algín año? } \\ \text { que tenia antes de }\end{array} & \text { grado? } \\ \text { comenzarlo? } & & \end{array}$

\begin{tabular}{|c|c|c|c|c|}
\hline $\begin{array}{l}\text { ¿Cómo eran sus } \\
\text { expectativas antes de } \\
\text { comenzar el grado? }\end{array}$ & $\begin{array}{l}\text { Correlación de } \\
\text { Pearson }\end{array}$ & -.049 & .105 & .080 \\
\hline $\begin{array}{l}\text { Una vez que ha } \\
\text { cursado algún año del } \\
\text { grado, ¿Sigue } \\
\text { manteniendo el mismo } \\
\text { pensamiento que tenía } \\
\text { antes de comenzarlo? }\end{array}$ & $\begin{array}{l}\text { Correlación de } \\
\text { Pearson }\end{array}$ & 1 & $.654^{* *}$ & $.497^{* *}$ \\
\hline $\begin{array}{l}\text { ¿Ha cambiado su } \\
\text { sentimiento por el } \\
\text { grado tras cursar } \\
\text { algún año? }\end{array}$ & $\begin{array}{l}\text { Correlación de } \\
\text { Pearson }\end{array}$ & & 1 & $.654^{\circ *}$ \\
\hline $\begin{array}{l}\text { ¿Ha cambiado su } \\
\text { comportamiento tras } \\
\text { cursar algín año del } \\
\text { grado? }\end{array}$ & $\begin{array}{l}\text { Correlación de } \\
\text { Pearson }\end{array}$ & & & 1 \\
\hline
\end{tabular}

** La correlación es significativa en el nivel 0.001 (bilateral)

Con respecto a la relación de los componentes de la actitud con las expectativas reales, en la Tabla 13, podemos observar que se refleja una relación significativa interescalar entre algún componente de la actitud y las expectativas tras cursar algún año del grado. Nuevamente en esta tabla podemos comprobar que existe la relación significativa intraescalar comentada anteriormente entre los componentes de la actitud.

En lo referente a los componentes de la actitud que presentan relación con las expectativas reales de los estudiantes, podemos observar que:

Existe una relación estadísticamente significativa en el par factor afectivo vs expectativas reales. $(\mathrm{r}=.256$, significación de 0,001$)$.

Existe una relación estadísticamente significativa en el par factor comporta- mental vs expectativas reales. $(r=.332$, significación de 0,001$)$.

Existe una relación estadísticamente significativa en el par factor comportamental vs expectativas reales. $(r=.332$, significación de 0,001$)$.

Tabla 13

Relación de los componentes de la variable actitud con las expectativas reales

\begin{tabular}{|c|c|c|c|c|}
\hline & & $\begin{array}{l}\text { iHa cambiado su } \\
\text { sentimiento por el } \\
\text { grado tras cursar algún } \\
\text { año? }\end{array}$ & $\begin{array}{l}\text { ¿Ha cambiado su } \\
\text { comportamiento tras } \\
\text { cursar algún año del } \\
\text { grado? }\end{array}$ & $\begin{array}{l}\text { Una vez cursado } \\
\text { algun año del } \\
\text { grado, } \\
\text { ¿Considera que } \\
\text { se han cumplido } \\
\text { sus expectativas? }\end{array}$ \\
\hline $\begin{array}{l}\text { Una vez que ha cursado } \\
\text { algún año del grado, ¿Sigue } \\
\text { manteniendo el mismo } \\
\text { pensamiento que tenia } \\
\text { antes de comenzarlo? }\end{array}$ & $\begin{array}{l}\text { Correlación de } \\
\text { Pearson }\end{array}$ & $.654^{\prime \prime}$ & .497" & .179 \\
\hline $\begin{array}{l}\text { ¿Ha cambiado su } \\
\text { sentimiento por el grado } \\
\text { tras cursar alguin año? }\end{array}$ & $\begin{array}{l}\text { Correlación de } \\
\text { Pearson }\end{array}$ & 1 & $.654^{*}$ & $.256^{*}$ \\
\hline $\begin{array}{l}\text { ¿Ha cambiado su } \\
\text { comportamiento tras cursar } \\
\text { algín año del grado? }\end{array}$ & $\begin{array}{l}\text { Correlación de } \\
\text { Pearson }\end{array}$ & & 1 & $.332^{*}$ \\
\hline $\begin{array}{l}\text { Una vez cursado algún año } \\
\text { del grado, ¿Considera que } \\
\text { se han cumplido sus } \\
\text { expectativas? }\end{array}$ & $\begin{array}{l}\text { Correlación de } \\
\text { Pearson }\end{array}$ & & & 1 \\
\hline
\end{tabular}

En síntesis, no existe relación entre los componentes de la actitud y las expectativas de los estudiantes antes de comenzar el grado, sin embargo, sí existe relación entre los factores afectivos y comportamentales de las actitudes y las expectativas de los estudiantes tras finalizar algún año del grado.

Se ha comprobado en los resultados que, tras finalizar algún año del grado, la mayoría de los estudiantes que mantienen o cambian su pensamiento, afecto o comportamiento hacia el grado presentan más expectativas positivas que negativas.

Bloque 2. Resultados cualitativos

A continuación, nos interesa conocer las opiniones de los estudiantes con respecto al grado. Por ello, las últimas preguntas del cuestionario son de carácter cualitativo y con éstas se les ha dado a los estudiantes la oportunidad de argumentar todas las opiniones que tienen sobre el grado, posibilidades de mejora y cambio, pensamiento futuro sobre oportunidad laboral etc. Por todo esto, pasamos a analizar las preguntas semiabiertas y abiertas formuladas a los estudiantes.

Los comentarios de alumnos/as que se mostrarán en las figuras, que se pueden observar a continuación, han sido obtenidos dentro de la encuesta que previamente se les pasó a los estudiantes.

La primera pregunta de carácter cualitativo que se le formuló a los estudiantes fue la siguiente: ¿Se arrepiente de haber elegido Turismo como carrera universitaria? ¿Por qué?

Esta pregunta se dejó como una pregunta abierta, con lo cual los estudiantes podían responder todo lo que pensaran. De las 105 respuestas obtenidas, se han seleccionado aquellas que se han dado con más frecuencia.

Cómo se puede observar en los comentarios de los/las alumnos/as, expuestos en la siguiente Figura 1, es mayor la cantidad de estudiantes que no se arrepienten de haber elegido este grado. Aquellos que se arrepienten declaran que es debido a que no han entrado al grado por vocación y porque se sienten decepcionados, ya que consideran que se puede trabajar en el sector sin necesidad de cursar el grado. 
Figura 1

Arrepentimiento de los estudiantes

\begin{tabular}{|c|c|}
\hline $\begin{array}{l}\text { ESTUDIAN- } \\
\text { TES } \\
\text { SEGÚN } \\
\text { ORDEN DE } \\
\text { RESPUES- } \\
\text { TA AL } \\
\text { CUESTIO- } \\
\text { NARIO } \\
\end{array}$ & OPINIONES \\
\hline Estudiante: 1 & $\begin{array}{l}\text { "En mi caso me arrepiento de haber elegido este grado, } \\
\text { aunque fuera por descarte, pero me gustaría que hubie- } \\
\text { sen hecho más hincapié en los idiomas." }\end{array}$ \\
\hline Estudiante: 5 & $\begin{array}{l}\text { "Me arrepiento y me siento mal, porque realmente es la } \\
\text { carrera que siempre he querido estudiar, pero creo que } \\
\text { la UAL no sabe motivar a los/las alumnos/as lo sufi- } \\
\text { ciente en lo que respecta a cursar esta carrera, con lo } \\
\text { cual la desmotivación que sientes al cursar el grado me } \\
\text { ha hecho sentirme arrepentida de cursar el grado y ver } \\
\text { que ha sido una pérdida de tiempo, el cual podía haberlo } \\
\text { invertido en una carrera que si sepan darle valor." }\end{array}$ \\
\hline $\begin{array}{l}\text { Estudiantes: } \\
7,25 \text { y } 82\end{array}$ & $\begin{array}{l}\text { "No me arrepiento, porque el grado tiene asignaturas } \\
\text { muy variadas y eso me ha gustado." }\end{array}$ \\
\hline $\begin{array}{l}\text { Estudiantes: } \\
9,33,56 \text { y } 74\end{array}$ & "No, aunque hay asignaturas que pienso que sobran." \\
\hline $\begin{array}{l}\text { Estudiante: } \\
16\end{array}$ & $\begin{array}{l}\text { "No, debido a que es una meta que siempre quise cum- } \\
\text { plir." }\end{array}$ \\
\hline $\begin{array}{l}\text { Estudiante: } \\
17\end{array}$ & "No, es la mejor carrera, estudiamos de todo." \\
\hline 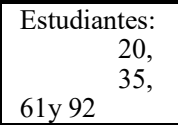 & "No me arrepiento, pero estoy decepcionada." \\
\hline $\begin{array}{l}\text { Estudiantes: } \\
22 \text { y } 36\end{array}$ & $\begin{array}{l}\text { "No, pero el nivel de idiomas impartido y la estructura } \\
\text { de la carrera es bastante pobre en comparación con otras } \\
\text { universidades." }\end{array}$ \\
\hline $\begin{array}{l}\text { Estudiante: } \\
44\end{array}$ & $\begin{array}{l}\text { "No, porque es un grado muy versátil, por lo que le } \\
\text { viene bien a una persona tan indecisa como yo." }\end{array}$ \\
\hline $\begin{array}{l}\text { Estudiante: } \\
48\end{array}$ & $\begin{array}{l}\text { "No, porque he aprendido muchas cosas, sobre todo de } \\
\text { informática o arte." }\end{array}$ \\
\hline $\begin{array}{l}\text { Estudiante: } \\
50\end{array}$ & $\begin{array}{l}\text { "No, porque me he sorprendido a mí misma y he encon- } \\
\text { trado una de mis vocaciones." }\end{array}$ \\
\hline $\begin{array}{l}\text { Estudiante: } \\
57\end{array}$ & $\begin{array}{l}\text { "No, porque me gustan e interesan mucho las asignaturas } \\
\text { y creo que en un futuro }\end{array}$ \\
\hline & $\begin{array}{l}\text { Voy a poder aplicar de forma práctica lo que estoy } \\
\text { aprendiendo ahora." }\end{array}$ \\
\hline $\begin{array}{l}\text { Estudiantes: } \\
4 \text { y } 68\end{array}$ & "No, porque tiene muchas salidas." \\
\hline $\begin{array}{l}\text { Estudiante: } \\
83\end{array}$ & $\begin{array}{l}\text { "Si, hay trabajo que igual conseguiría sin el título uni- } \\
\text { versitario, que es el que acabas haciendo tras la carrera. } \\
\text { Carrera mal organizada, asignaturas absurdas y mal } \\
\text { organizadas. Aun así, también hay cosas buenas, pero } \\
\text { brilla por su ausencia." }\end{array}$ \\
\hline $\begin{array}{l}\text { Estudiantes: } \\
11 \text { y } 86\end{array}$ & $\begin{array}{l}\text { "Si, me hubiese gustado más estudiar algo por lo que } \\
\text { tuviese vocación." }\end{array}$ \\
\hline $\begin{array}{l}\text { Estudiante: } \\
91\end{array}$ & $\begin{array}{l}\text { "Si, no tiene "identidad" propia. Es como coger un poco } \\
\text { de "X" grados y juntarlos en este caso con un grado de } \\
\text { dificultad mínimo." }\end{array}$ \\
\hline $\begin{array}{l}\text { Estudiante: } \\
103\end{array}$ & $\begin{array}{l}\text { "Si, porque mis expectativas de tanto el oficio como } \\
\text { idiomas eran muy altas (ya que estamos realizando una } \\
\text { carrera) y al finalizar la carrera me he dado cuenta de } \\
\text { que no nos han enseñado eso." }\end{array}$ \\
\hline
\end{tabular}

La siguiente pregunta que se le realizó a los estudiantes fue si modificarían algo del grado, y, en caso positivo, qué modificarían, esto último se les preguntó a los/las alumnos/as, mediante una pregunta abierta, al igual que en la pregunta anterior, se han seleccionado las respuestas que se han dado con más frecuencia.

En la Figura 2 observamos por los comentarios de los/las alumnos/as que, la gran mayoría coincide en que deberían impartirse más idiomas con un mayor nivel de dificultad, más diversidad de prácticas en empresa y más asignaturas relacionadas con la atención al cliente.

Figura 2

Modificación del grado

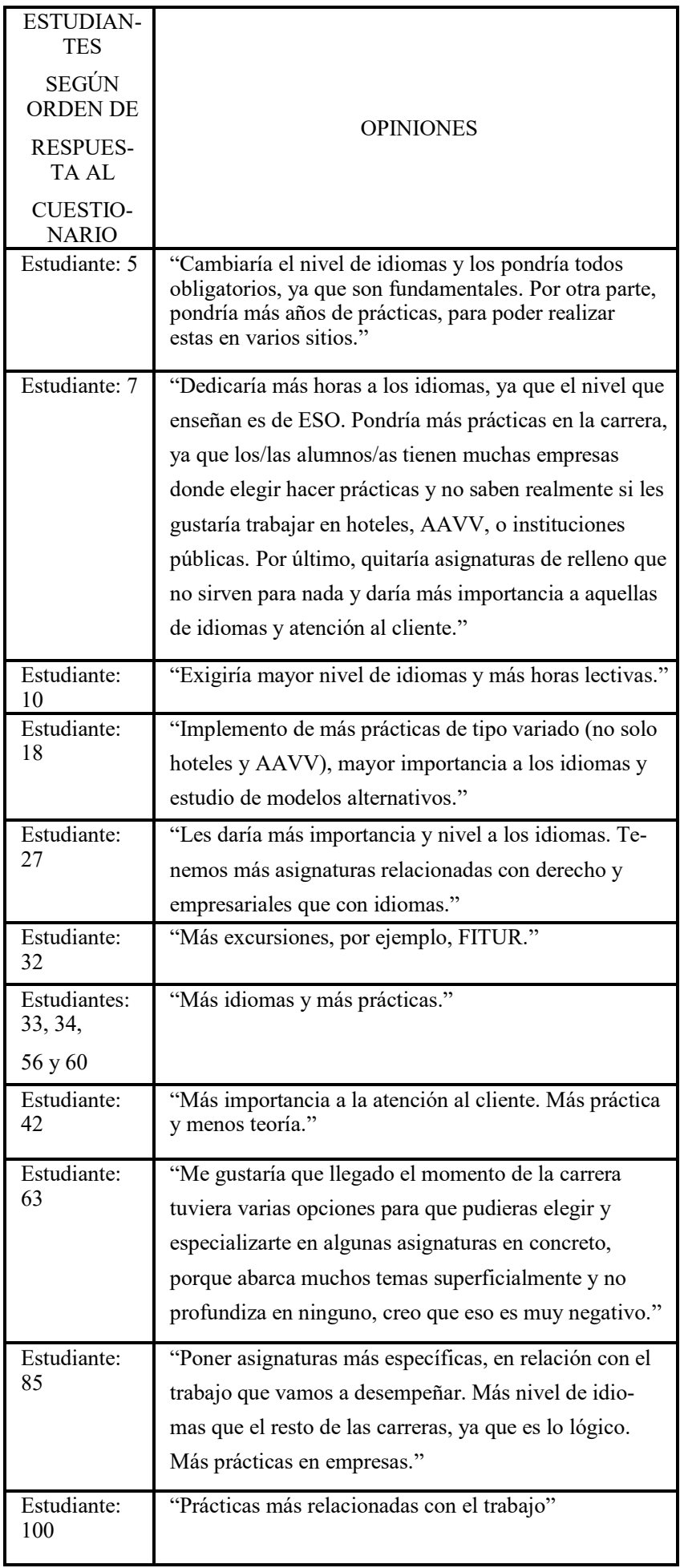


Para finalizar la encuesta, la última pregunta que se les hizo a los encuestados fue si consideraban que el Grado en Turismo, estaba realmente valorado por la sociedad y por qué. Esta cuestión se dejó como pregunta abierta, para que los estudiantes pudieran explicar todo lo que pensaban. De todos los comentarios de los/las alumnos/as, se han seleccionado como en los casos anteriores aquellas respuestas más frecuentes.

Como podemos observar en los comentarios de los estudiantes de la Figura 3 , únicamente aquellos/as alumnos/as que consideran que el grado no está valorado son los que han dado sus motivos.

Para resumir los comentarios de estos, los/las alumnos/as consideran que Turismo no está valorado por la sociedad, porque esta piensa que es un grado fácil y que se realiza sin esfuerzo, que las universidades no saben despertar el interés por el grado y que hay demasiado intrusismo y cursos de formación con los que se puede acceder a los mismos puestos de trabajo que te facilita el grado.

Figura 3

Valoración del grado por parte de la sociedad

\begin{tabular}{|c|c|}
\hline $\begin{array}{c}\text { ESTUDIAN- } \\
\text { TES } \\
\text { SEGÚN OR- } \\
\text { DEN DE RES- } \\
\text { PUESTA AL } \\
\text { CUESTIONA- } \\
\text { RIO } \\
\end{array}$ & OPINIONES \\
\hline Estudiante: 1 & $\begin{array}{l}\text { "Creo que no está lo valorado que se merece porque hay } \\
\text { personas que realizan los mismos puestos de trabajo sin } \\
\text { el grado que los ya graduados." }\end{array}$ \\
\hline Estudiante: 5 & $\begin{array}{l}\text { "No. El grado en turismo es uno de los menos valorados } \\
\text { ya que no genera interés." }\end{array}$ \\
\hline Estudiante: 8 & $\begin{array}{l}\text { "No. Existen módulos superiores (AAVV, alojamiento, } \\
\text { guía turístico) que te dan las mismas salidas y están } \\
\text { mejor organizados." }\end{array}$ \\
\hline Estudiante: 12 & $\begin{array}{l}\text { "No. La gente no se da cuenta de que el turismo contri- } \\
\text { buye a un alto porcentaje de la economía en España, es } \\
\text { decir, es uno de los oficios que más dinero da al país." }\end{array}$ \\
\hline Estudiante:14 & $\begin{array}{l}\text { "No. La gente piensa que no hacemos nada y que es } \\
\text { una carrera de mentira, cuando en realidad se trabaja } \\
\text { igual o más que en otras carreras, ya que tenemos que } \\
\text { tocar todo tipo de asignaturas. En mi opinión es de las } \\
\text { carreras más completas y en la que más se puede } \\
\text { aprender, encima hay muchas salidas laborales. Esas } \\
\text { personas de la sociedad que critican mi carrera son los } \\
\text { primeros que quieren alojarse en un hotel con todo a su } \\
\text { gusto o van a AAVV u otros servicios turísticos. Estos } \\
\text { deben concienciarse que tras esa imagen hay muchas } \\
\text { personas trabajando y estudiando." }\end{array}$ \\
\hline Estudiante: 21 & $\begin{array}{l}\text { "No. La visión de la sociedad acerca de este grado } \\
\text { suele ser porque las personas ven del turismo una } \\
\text { actividad de ocio y no un trabajo excesivamente serio. } \\
\text { Por otra parte, hay que añadir, que es un grado muy } \\
\text { joven, poco reconocido y valorado." }\end{array}$ \\
\hline Estudiante: 33 & $\begin{array}{l}\text { "No, hay demasiado intrusismo y demasiados cursos } \\
\text { que desprestigian el grado, ya que con ellos realizas el } \\
\text { mismo trabajo que un graduado en la universidad y no } \\
\text { me parece correcto. Hay que darle más valor a la carre- } \\
\text { ra, no únicamente ofrecer trabajos de recepción." }\end{array}$ \\
\hline
\end{tabular}

\begin{tabular}{|c|c|}
\hline $\begin{array}{l}\text { ESTUDIAN- } \\
\text { TES } \\
\text { SEGÚN OR- } \\
\text { DEN DE RES- } \\
\text { PUESTA AL } \\
\text { CUESTIONA- } \\
\text { RIO }\end{array}$ & OPINIONES \\
\hline Estudiante: 41 & $\begin{array}{l}\text { "No, la mayoría de las personas opina que no es } \\
\text { necesaria una carrera para trabajar en el sector, y } \\
\text { está poco valorada por el resto de los estudiantes, } \\
\text { no nos toman en serio y a veces no respetan." }\end{array}$ \\
\hline Estudiante: 58 & $\begin{array}{l}\text { "No, pero tampoco lo está por la UAL. Para la } \\
\text { facultad de económicas, turismo es el grado al que } \\
\text { menor atención prestan, siempre nos dan todo lo } \\
\text { peor y no reconocen nuestros méritos. Es muy } \\
\text { normal que, si la propia facultad no nos respeta y } \\
\text { valora, no lo hagan los demás." }\end{array}$ \\
\hline Estudiante: 63 & $\begin{array}{l}\text { "No, piensan que es una carrera-comodín, que si } \\
\text { nos metemos ahí es porque no nos dan la primera } \\
\text { opción o porque es fácil. Ese concepto hay que } \\
\text { cambiarlo. iiiValorad más esta carrera por dios!!!" }\end{array}$ \\
\hline Estudiante: 75 & $\begin{array}{l}\text { "No, porque la gente no es consciente de la impor- } \\
\text { tancia que tiene, sobre todo en una ciudad como } \\
\text { Almería, que gran parte de los ingresos que se } \\
\text { obtienen son del turismo. En todas las universida- } \\
\text { des deberían darle más importancia y despertar el } \\
\text { interés de la gente por estudiar el grado." }\end{array}$ \\
\hline Estudiante: 81 & $\begin{array}{l}\text { "No, somos el último punto del mundo. Demasia- } \\
\text { das horas y mal pagado." }\end{array}$ \\
\hline Estudiante: 96 & $\begin{array}{l}\text { "No, la gente piensa que vas a jugar y a viajar no a } \\
\text { estudiar." }\end{array}$ \\
\hline $\begin{array}{l}\text { Estudiantes: } 3 \text {, } \\
38,39,57,66, \\
82,102,104 \\
\text { y105 }\end{array}$ & "Si." \\
\hline
\end{tabular}

En síntesis, hemos observado en los resultados, que la mayoría de los/ las alumnos/as no se arrepienten de haber elegido Turismo como carrera universitaria, pero mejorarían el nivel de idiomas impartido en la universidad e incluirían más horas de práctico. Por último, la gran mayoría de los/las alumnos/as está de acuerdo en que el grado en Turismo no está realmente valorado por la sociedad.

\section{Conclusiones}

Con respecto al primer objetivo de esta investigación, “conocer cuáles son los componentes de la actitud (factor cognitivo, factor comportamental y factor afectivo) que más valoran los estudiantes en el Grado en Turismo de la Universidad de Almería", tras analizar los tres factores, hemos observado que en lo referente al primer componente, el factor cognitivo, el mayor pensamiento que tenían los/las alumnos/as sobre el grado era aprender diferentes idiomas y aprender sobre el sector turístico, coincidiendo una vez más estos resultados con los motivos por los que los estudiantes eligieron estudiar este grado. Los/ las alumnos/as consideran que se deberían realizar más prácticas de empresa y mejorar e incluir más idiomas dentro del grado, esto es algo imprescindible para muchas carreras universitarias, ya que autores 
como Liesa y Vived (2016), docentes en la Facultad de ciencias Humanas y de la Educación de Huesca, Universidad de Zaragoza, defienden que, la duración y la funcionalidad de las prácticas deberían reforzarse y que el enfoque de las asignaturas debería ganar en realismo, acercar a los/las alumnos/as a la realidad (casos, experiencias...), incluir aprendizajes sobre el "saber hacer" y tener una orientación adecuada hacia su trabajo futuro. Esto explica que, en los resultados, observamos cómo para la mayoría de los/las alumnos/as, este pensamiento ha cambiado, por los que podemos decir que éstos probablemente no han aprendido en el grado aquello que tenían pensado cuando lo comenzaron.

Como conclusiones del segundo componente de la actitud, el factor comportamental, hemos observado en los resultados que la mayoría de los estudiantes tenían un comportamiento positivo hacia el grado pues se mostraban curiosos y sin miedo al fracaso, pero un porcentaje elevado de estos coincidían en que se enfrentaban al grado con miedo a no superar las asignaturas, seguidos de varios alumnos/as cuyo comportamiento era indiferente. Estos altos porcentajes pueden deberse a que como la mayoría de los/las alumnos/ as no entraron por vocación al grado, éstos no se mostraban totalmente confiados. Posteriormente, hemos comprobado que varios alumnos/as tras realizar algún año del grado, mantienen el mismo comportamiento que al principio.

En lo que respecta al tercer componente, el factor afectivo, la mayoría de los encuestados coinciden en que se sentían atraídos hacia el grado antes de comenzarlo, lo cual nos muestra que estos tenían un sentimiento positivo hacia éste. El mismo número de alumnos/as coinciden en un sentimiento de atracción hacia la UAL y no tener ningún sentimiento hacia el grado, esto puede deberse a que muy pocos alumnos entraron al grado por vocación. Según Ramos (2012) la vocación está relacionada con el sueño, deseo o anhelo, que quiere alcanzar una persona, es decir, aquella profesión o carrera que quieres lograr. Para estudiar cualquier carrera, es necesario tener un mínimo de interés, tanto por la carrera elegida, como por las profesiones a las que la carrera da salida, de no ser esto así los estudiantes podrán encontrar obstáculos dentro del grado que les cree desmotivación, y falta de sentimiento hacia éste. En la pregunta que se les realiza a los/las alumnos/as sobre sus sentimientos tras cursar algún año del grado hemos observado en los resultados como para la mayoría de los/las alumnos/as, el sentimiento ha cambiado.

Los componentes más valorados de la actitud para los estudiantes son el factor cognitivo y el factor comportamental, ya que, como hemos podido ver en los resultados, éstas son las dimensiones que presentan valores (porcentajes) más altos, aunque el factor afectivo está también muy valorado por los estudiantes.

En lo que respecta al segundo objetivo, "estudiar cuáles son las expectativas de los estudiantes del grado en Turismo de la Universidad de Almería", hemos observado que la gran mayoría de los estudiantes presentaban expectativas positivas antes de comenzar el grado, siendo un menor número de estudiantes, aquellos que presentaban expectativas negativas, estos porcentajes pueden corresponderse probablemente con aquellos estudiantes que entraron al grado por descarte o por no poder entrar en su primera opción. Como hemos podido observar en los resultados, la mayoría de los estudiantes consideran que no se han cumplido sus expectativas, esto puede deberse a que, los/las alumnos/as no han visto reflejado en el grado aquello a lo que le daban más importancia antes de comenzarlo (aprender sobre el sector turístico e idiomas).

Tras analizar las expectativas de los estudiantes por curso del grado, hemos observado que, para los/las alumnos/as de primer curso, se han cumplido altamente sus expectativas, seguido de los/las alumnos/as de tercer curso, para los cuales, también, se han cumplido sus expectativas. Para la mayoría de alumnos/as de segundo y cuarto curso no se han cumplido sus expectativas, siendo mayor el porcentaje de los/las alumnos/as de cuarto curso, esto puede ser debido a que éstos son los que han pasado por todos los años de carrera, han cursado las prácticas de empresa y todas las asignaturas de idiomas impartidas. Como hemos visto en los comentarios de los/las alumnos/as, en el caso de las prácticas de empresa, estos consideran que hay muy pocas horas, y que éstas deberían realizarse en más de un año y en más de una empresa, ya que los/las alumnos/as a la hora de elegir dónde realizar las prácticas, se enfrentan a un debate interno a causa del desconocimiento de las actividades que se llevan a cabo dentro de cada empresa y una vez elegidas éstas, piensan en qué habrían realizado si hubieran elegido otra empresa.

En el caso del nivel de idiomas, los/las alumnos/as muestran su insatisfacción en los comentarios, ya que argumentan que éstos no son lo que ellos esperaban. Una gran parte de los estudiantes entraron al grado esperando aprender varios idiomas y una vez dentro de éste, ellos consideran que hay muy pocas horas lectivas de idiomas dentro del grado y que el nivel de éstos es muy bajo. Todo esto ha podido provocar tal decepción en los estudiantes que les lleva a considerar que sus expectativas más que no ser cubiertas, han pasado a ser expectativas negativas hacia el grado. Toda la información comentada anteriormente, se ve reforzada por los datos cualitativos.

Con respecto al tercer objetivo, "investigar la relación que existe entre los factores actitudinales (cognitivo, comportamental y afectivo) y las expectativas de los estudiantes con respecto al Grado en Turismo", hemos podido comprobar en los resultados que no existe ninguna relación entre la actitud de los estudiantes y sus expectativas antes de comenzar el grado, esto puede ser debido a factores externos que condicionan las decisiones y la forma de actuar de los estudiantes, ya que éstos comienzan el grado con diferentes expectativas respecto al tipo de educación y al futuro laboral que tendrán. La mayoría de las veces los estudiantes tienen expectativas que no son realistas, ya que los motivos por los que deciden entrar al grado cada año son diferentes (Pichardo, García- Berben, de la Fuente y Justicia, 2007).

Por otra parte, hemos observado que sí existe relación entre la actitud de los estudiantes y las expectativas reales de éstos, concretamente éstas presentan relación con el factor afectivo y con el factor comportamental, esto podría deberse a que, durante la realización de los cursos, los estudiantes han ido cambiando su comportamiento y su sentimiento con respecto al grado, y con estos, las expectativas que tenían antes de comenzarlo. Como hemos podido apreciar en los resultados, las actitudes y expectativas de los estudiantes han ido variando, siendo positivas y negativas en diferentes cursos del grado.

En lo referente al motivo por el que los estudiantes eligieron Turismo como grado universitario, hemos observado que la gran parte de los/las alumnos/as han optado por este grado porque se sienten atraídos por trabajar en el sector turístico, y esperan aprender diferentes idiomas dentro del grado. Todo esto explica que, como hemos podido ver en los resultados, los/las alumnos/as no se arrepienten de haber elegido este grado, pero sí que mejorarían dentro de éste, más prácticas de empresa y la cantidad y el nivel de idiomas, ya que éstos eran los motivos por los que los/las alumnos/as elegían estudiar el grado. Por el contrario, un bajo porcentaje de alumnos/as, eligieron el grado por vocación lo cual podría suponer una explicación a por qué varios alumnos/as antes de comenzar el grado no presentaban ninguna expectativa hacia éste, aunque hemos visto que con el paso de los cursos esto ha cambiado y hay un menor número de alumnos/as que no presentan expectativas. En cuanto a la pregunta que se les realizó a los estudiantes con respecto a si habían realizado la beca Erasmus que les ofrecía la universidad, los pocos alumnos/as que disfrutaron de ésta han comentado que en su universidad de Erasmus el nivel académico ha sido mayor, la posible explicación de esto puede ser que, al viajar al extranjero, la dificultad del idioma les haya hecho sentir un mayor grado de complejidad a la hora de estudiar las asignaturas. Son varios los estudios en los que se defienden que uno de los principales motivos por los que los estudiantes realizan una beca Erasmus, es con el objetivo de aprender o mejorar un idioma y no sólo por realizar parte de sus estudios en el extranjero (Belvis, Pineda y Moreno, 2007).

Como hemos observado en los resultados, la gran mayoría de los encuestados considera que, una vez acabado el grado, van a tener dificul- 
tad para trabajar dentro del sector turístico, pues numerosos artículos puntúan el grado en Turismo junto con Forestales, las carreras universitarias con menos salidas laborales. Según Álvarez (2014), en las dos carreras universitarias, la mitad de los titulados han terminado trabajando en empleos para los que no necesitaban ni una cualificación universitaria ni ningún estudio previo más allá del graduado escolar. Lo cierto es que artículos como los de este tipo hacen que disminuyan las expectativas de los/las alumnos/as y que éstos cada vez se muestren menos interesados en elegir el Grado en Turismo como carrera universitaria.

Con respecto a las preguntas abiertas realizadas a los estudiantes, hemos podido observar el descontento de los estudiantes en cuanto a los idiomas y las prácticas, pero que aún y con esto, no se arrepienten de haber elegido el grado como carrera universitaria.

En lo referente a la pregunta en la que se cuestiona si el grado está realmente valorado por la sociedad, hemos podido comprobar que los/las alumnos/ as consideran que éste no está realmente valorado y tachan que haya intrusismo dentro del sector (ver información cualitativa) o que con la simple realización de cursos relacionados con éste es fácil llegar a puestos de trabajo a los que aspira un graduado universitario. Esto es algo muy criticado por aquellos que pertenecen al sector ya que, tanto en Almería como en Andalucía y España, el Turismo es una de las principales fuentes económicas. Según Hosteltur (2017), la industria turística ha sido la salvadora de la economía española durante esta década, que comenzó duramente marcada por la recesión.

\section{Limitaciones}

La primera limitación encontrada dentro de este trabajo es la falta de información sobre el tema elegido, ya que no se han encontrado estudios previamente realizados sobre expectativas y actitud de estudiantes del grado en Turismo ni de otros grados.

Otras de las limitaciones encontradas son la falta de un instrumento previamente validado y la falta de estudios que combinen la metodología cuantitativa y cualitativa, que ayuden a la elaboración del cuestionario.

También el tiempo para la realización de la investigación ha sido una de las principales limitaciones de este estudio.

La siguiente limitación encontrada es la falta de implicación por parte de la mayoría de los estudiantes de Turismo, ya que únicamente ha respondido al cuestionario un cuarto de la muestra seleccionada.

Por último, otra de las limitaciones encontradas, es el coste del programa utilizado para el análisis de datos, IBM SPSS.

Perspectivas de futuro e implicaciones prácticas

Como perspectivas de futuro de esta investigación se puede proponer la validación de la herramienta utilizada para este tipo de investigación. Otra de las perspectivas podría ser una ampliación de la muestra para conocer las opiniones de más estudiantes de Turismo que realicen el grado en otras universidades. También, seguir indagando en las expectativas y actitudes de los estudiantes sería de interés, pues sería bueno seguir averiguando qué motivos han llevado a los estudiantes a cambiar su actitud y expectativas hacia el grado.

Este trabajo de investigación puede traer numerosas implicaciones prácticas futuras, pues puede ayudar a muchos alumnos/as con la elección de este grado como carrera universitaria, ya que esta investigación muestra la experiencia de otros alumnos/as, también puede ayudar a la mejora de las asignaturas que se imparten dentro del grado, pues muchos de los/las alumnos/ as encuestados consideran que, se deberían reforzar los idiomas y dedicarles más horas lectivas porque estos son un pilar fundamental dentro del sector turístico, esto podría llevarse a cabo iniciando programas de intercambio de alumnos o realizando mejoras dentro del plan de becas de movilidad. Al ser Turismo uno de los grados que más relación tiene con los idiomas y los viajes, en éste se debería ofertar un mayor número de becas para poder realizar parte de los estudios en un país extranjero. Éstas serían unas buenas opciones para la motivación y el incentivo de los/las alumnos/as. Como otra implicación, también, se puede tener en cuenta mejorar el formato de las prácticas de empresa y que éstas se impartan más de un año y tengan un horario más amplio. Sería bueno para los/las alumnos/as que cada año del grado tuvieran la oportunidad de realizar un período de prácticas en un establecimiento diferente, tanto hoteles como agencias de viajes o instituciones públicas, y que así éstos realmente pudieran conocer cada uno de éstos y comparar entre ellos, para poder tener una idea profesional más definida, una vez finalizado el grado.

Por último, pero no menos importante, este trabajo puede ayudar a que el grado en Turismo sea más valorado por la sociedad, ya que como hemos podido ver en los resultados anteriores, los/las alumnos/as consideran que es un grado que está muy poco valorado por la sociedad y el turismo es muy importante para la economía y la prosperidad del país.

Para terminar, hemos podido observar que, en general, existe una visión global positiva del grado por parte de los estudiantes y que gracias a esta investigación se pueden atender las debilidades de este grado de cara a una futura mejora.

\section{Referencias bibliográficas}

Alonso, J. (1999). Comportamiento del consumidor. Madrid: ESIC

Álvarez, P., González M., y López, D. (2009). La enseñanza universitaria y la formación para el trabajo: Un análisis desde la opinión de los estudiantes. Paradígma, 30(2), 7-20. Recuperado de: http://www.scielo.org.ve/scielo.php? script $=$ sci_arttext\&pid=S101122512009000200002\&lng=es\&t lng=es.

Álvarez, P. (2014). Turismo y Forestales son las carreras con peores salidas. El País. Recuperado de: Https://politica.elpais.com/ politica/2014/11/24/actualidad/1416860826_272035.html

Belvis, E., Pineda, P., y Moreno, M. (2007). La participación de los estudiantes universitarios en programas de movilidad: factores y motivos que la determinan. Revista Iberoamericana de Educación, 42(5), 1-14. Recuperado de: Https://rieoei.org/ $\mathrm{RIE} /$ article/view/2397

Cosacov, E. (2007). Diccionario de Términos Técnicos de Psicología. Córdoba: Brujas.

Eagly, A. H. y Chaiken, S. (1998). Attitude structure and function. En D. T. Gilbert, S. T. Fiske and G. Lindzey (Eds.), The Handbook of Social Psychology (4th edn. Vol. 1, pp. 269-322). New York: McGraw-Hill.

Hosteltur (2017). El turismo salva a la economía española esta década Recuperado de: https://www.hosteltur.com/125733_turismosalva-economia-espanola-esta-decada.html

Liesa, M. y Vived, E. (2016). El nuevo prácticum del grado de magisterio. Aportaciones de alumnos y profesores. Estudios sobre Educación, 18, 201-228.

Merhi, R. (2011). Expectativas del estudiantado en la universidad del nuevo milenio. Un proceso dinámico. La Cuestión Universitaria, 7, 23-31.

Morales, J. F. (2007). Relaciones entre actitud y conducta. En Psicología Social (pp. 208-213). España: S.A. Mcgraw-Hill/ Interamericana de España.

Nunnally, J. C. (1967). Psychometric theory. New York: McGraw-Hill

Pichardo, M. C., García, A. B., De la Fuente, J. y Justicia, F. (2007). El estudio de las expectativas en la universidad: análisis de trabajos empíricos y futuras líneas de investigación. Revista Electrónica de Investigación Educativa, 9(1), 1-16. Recuperado de: http://redie.uabc.mx/vol9no1/contenido-pichardo.html 
Ramos, A.L., (2012). La importancia de la vocación y la motivación del estudiante para su futuro profesional. Recuperado de: https:// www.educaweb.com/noticia/2012/02/13/importancia-vocacionmotivacionestudiante-su-futuro-profesional-5278/

Rodríguez, X., Martínez-Roget, F. y Pawlowska, E. (2012). Academic tourism demand in Galicia, Spain. En, C. Ryan. Tourism Management (pp. 583-1590). Hamilton, New Zealand: Board.

Seligman, M.E.P. (2005). La auténtica felicidad. Colombia: Imprelibros, S.A.

Sheldon, K. M., Fredrickson, B., Rathunde, K., Csikszentmihalyi, M., y Haidt, J. (1999). ¿Qué es la psicología positiva? Recuperado de: http://www.iepp.es/es/que-es-lapsicologia-positiva.html

Tribe, J, (1997). The indiscipline of tourism. En, J.Tribe. Annals of Tourism Research (pp. 638-657). Buckinghamshire, UK: Elsevier.

Walpole, R. E. y Myers, R. H. (1996) Probabilidad y Estadística. Ciudad de México, México: McGraw-Hill 